\title{
Design Challenges and Potentials of HTS Synchronous Motor for Superbus
}

\author{
S.O. Ani, H. Polinder, J.A. Ferreira \\ Electrical Energy Conversion \\ Delft University of Technology \\ Mekelweg 4, 2628 CD Delft, Netherlands
}

\author{
J.W. Ockels \\ Aerospace for Sustainable Engineering and Technology \\ Delft University of Technology \\ Kluyverweg 1, 2629 HS Delft, Netherlands
}

\begin{abstract}
This paper discusses the possibilities of applying high temperature superconducting (HTS) synchronous motor to Superbus, an alternative and sustainable type of public transportation developed at TU Delft. Two important factors within the Superbus drive that influence the operating range are weight and efficiency: increasing the weight results in larger roll resistance while the better the efficiency the larger the range. HTS rotating machines offer several advantages such as weight reduction and increased efficiency which can be exploited for special applications such as Superbus, where weight and volume reduction is important. In order to highlight the design challenges and potentials achievable by using HTS motor in Superbus an overview of the different approaches in the design of HTS machines is presented. Different rotor and stator topologies available in literature are discussed and comparison is made with conventional machines. The losses expected from the HTS motor are presented in comparison with conventional machines. It is concluded that it seems possible to achieve a reduction in losses and volume of about half compared with conventional machines.
\end{abstract}

\section{INTRODUCTION}

Superconductors have zero losses when they carry dc current and hence they can carry high current density. A high current density in the field windings means that a high magnetic field can be produced. This obvious advantage of a superconductor can be exploited in the design of electrical machines if we allow the field windings to carry de current. For this reason, the synchronous machine is an obvious choice for a superconducting machine as it uses dc current flowing in the field windings to produce a rotating magnetic field. Therefore, a superconducting motor is usually made of superconducting field windings in the rotor while the stator armature winding is made of copper.

A high temperature superconducting (HTS) motor is different from a low temperature superconducting (LTS) motor because of its higher operating temperature determined by the critical temperature of the superconductor material in the field windings. For LTS materials, it is necessary to cool the material to around liquid helium temperature of $4.2 \mathrm{~K}$ while HTS materials operate at a temperature of about $30 \mathrm{~K}$ or higher. In fact, it is the discovery of materials that are superconducting at higher temperature that has led to the recent resurgence in research on superconducting machines and in particular HTS machines. This has opened the door for the possibility to design a superconducting motor which is economically attractive but which was not the case when liquid helium was used as coolant.
The application of high temperature superconduction in machine design has been mainly concentrated on machines of large ratings (MW range) [1-9], where the increased costs incurred by using superconducting technology can be balanced by the advantages that will be gained, such as reduced motor volume and increased efficiency.

The objective of this paper is to discuss the possibilities of applying high temperature superconducting (HTS) motor to Superbus, whose power requirement is about $300 \mathrm{~kW}$. In this paper we will attempt to answer the following questions.

- Is it possible to apply high temperature superconducting technology to an electric vehicle like Superbus?

- What are the different design choices available and which is most suitable for Superbus?

- What are the expected losses in comparison with conventional machines?

First we will give a description of Superbus and its requirements. Then we will present a description of the major components of an HTS motor. Next, we will present a discussion on the available options in the design of HTS motors in comparison with conventional machines and its suitability for application in Superbus. Next, we will discuss the losses to be expected in the HTS motor compared with losses from conventional machine design. Finally, some conclusion will be drawn.

\section{DESCRIPTION OF SUPERBUS}

In this section we will give some background information about Superbus. Next, we will present the requirements of Superbus and why HTS motor is of interest.

Superbus is a novel and sustainable transportation vehicle in which aerospace and other advanced technologies are to be used in order to reduce the environmental impact of high speed public transport [10]. In inner cities, it drives emission-free while on open roads (highways) gaseous emissions as a result of the combustion of bio-fuels are allowed.

Figure 1 shows an artistic impression of Superbus. It is a luxurious coach which will deliver point-to-point service to customers with typical distances of $50 \mathrm{~km}$ to $200 \mathrm{~km}$ and should be able to drive at a speed of up to $250 \mathrm{~km} / \mathrm{h}$ on specially built infrastructure called super tracks. Figure 2 and table 1 gives some approximations of distances, speed and power requirements. 
Superbus is designed to achieve a high speed (up to 250 $\mathrm{km} / \mathrm{h}$ ) while the power required at that speed will be comparable with that of existing buses driving at $100 \mathrm{~km} / \mathrm{h}$. Therefore, it will combine low drag aerodynamic with a light weight structure and drive in a sustainable way. To achieve this attention is paid to two main sources of drag: aerodynamic drag and rolling resistance. Aerodynamic drag is determined by both the shape and the size, mainly frontal area. Reduction in the aerodynamic drag is achieved by streamlining the vehicle and reducing its height (Superbus is only $1.6 \mathrm{~m}$ high) [10], [11]. The rolling resistance is mainly determined by the weight of the vehicle and the tires. This informs the use of fiber reinforced composites and aerospace construction techniques which ensure that the weight of the vehicle and thus the rolling resistance can be reduced also [10], [11].

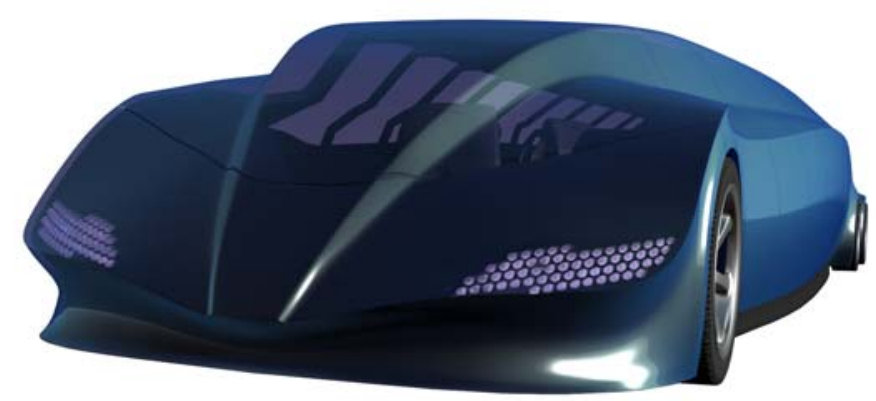

Figure 1. Artistic impression of Superbus

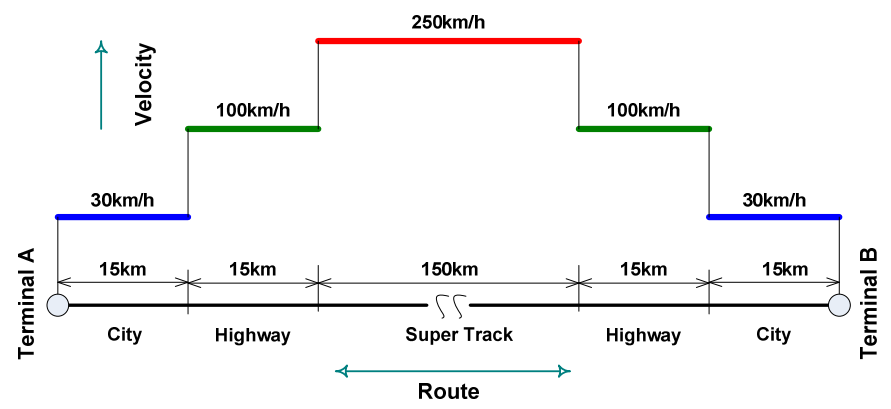

Figure 2: Superbus conceptual route

TABLE I

DIFFERENT TRACKS AND CALCULATED POWER REQUIREMENTS

\begin{tabular}{lllll}
\hline Track & Distance & Speed & $\begin{array}{l}\text { Traction } \\
\text { power }\end{array}$ & $\begin{array}{l}\text { Energy } \\
\text { required }\end{array}$ \\
\hline City & $2 * 15 \mathrm{~km}$ & $30 \mathrm{~km} / \mathrm{h}$ & $4.4 \mathrm{~kW}$ & $4.4 \mathrm{kWh}$ \\
Highway & $2 * 15 \mathrm{~km}$ & $100 \mathrm{~km} / \mathrm{h}$ & $25 \mathrm{~kW}$ & $7.5 \mathrm{kWh}$ \\
Super track & $150 \mathrm{~km}$ & $250 \mathrm{~km} / \mathrm{h}$ & $208 \mathrm{~kW}$ & $125 \mathrm{kWh}$ \\
Total & & & & $137 \mathrm{kWh}$ \\
Top speed & & $280 \mathrm{~km} / \mathrm{h}$ & $283 \mathrm{~kW}$ & \\
\hline
\end{tabular}

However, the potentials offered by the use of high temperature superconducting motor presents an opportunity to further reduce the weight of the vehicle while increasing the efficiency. Two important factors within the drive that influence the operating range are:
- weight - increasing the weight results in larger roll resistance

- $\quad$ efficiency - the better the efficiency the larger the range

Normally, the efficiency of a given motor can be improved by adding materials which also increases the weight. Is it possible to increase the efficiency without increasing the weight? Or better still, is it possible to increase the efficiency and reduce the weight?

\section{FEATURES OF HTS MOTOR}

This section will first give a discussion on why there is a renewed interest in superconducting motor in recent times. Then, we will give a description of the major components of an HTS motor.

The concept of superconducting machines has been implemented since the 1970s using low temperature superconductors (LTS) operating at liquid helium temperature of about $4.2 \mathrm{~K}[6,8,9,12$ and 13]; unlike a high temperature superconductor which is superconducting at temperatures above $27 \mathrm{~K}$. In particular, the discovery of high temperature superconductors having critical temperatures above liquid nitrogen temperature $(77 \mathrm{~K})$ means that liquid nitrogen can be used as coolant. Figure 3 shows values of critical temperature of some superconducting materials [14]. According to [4, 5 and 14], the use of liquid nitrogen is advantageous for a number of reasons.

- Nitrogen is cheap, easily available and easy to handle and manufacture.

- Superconductor 'quench' (a situation where a superconductor looses its superconductivity) is more likely to occur at a temperature of $4.2 \mathrm{~K}$ than at $77 \mathrm{~K}$ because the specific heat of materials is low at $4.2 \mathrm{~K}$. So that only a small quantity of heat is required to raise the temp of the superconductor above the limit that will result in 'quench'.

- Power required to keep superconductor at cryogenic temperature is reduced as the operating temperature increases. Also, the cool down time is reduced as the critical temperature increases: the time to cool to $77 \mathrm{~K}$ temperature is less than $1 / 4$ the time to cool to $4.2 \mathrm{~K}$ temperature.

According to the descriptions found in [15-19], the components of an HTS motor can be discussed under three major headings.

\section{A. Rotor assembly}

The rotor assembly is the most important part of the HTS motor because it houses the superconducting field winding which is held at cryogenic temperature and it is different from rotors of conventional machines. It consists of the following components.

- HTS field winding

- Support structure

- Torque tube

- Cryostat and EM shield

- Refrigeration component 


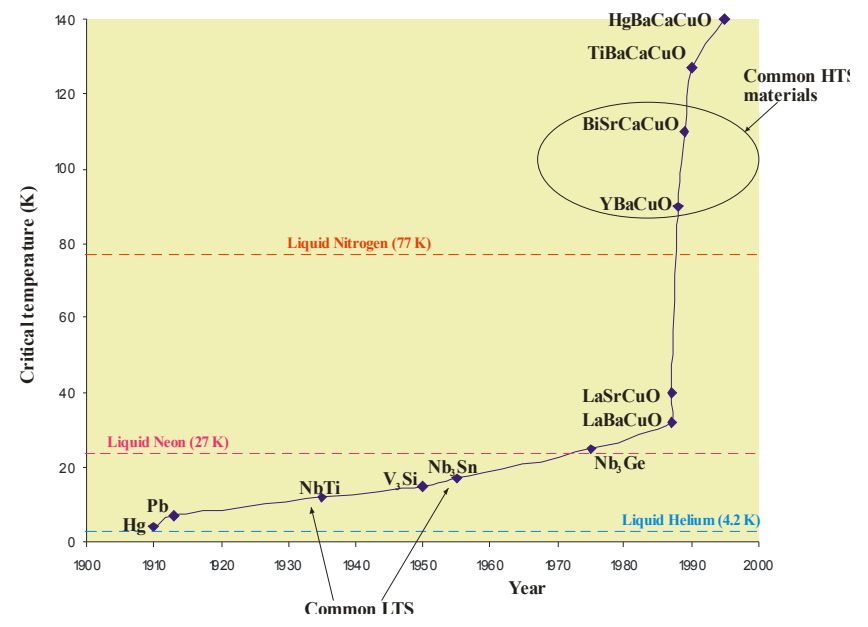

Figure 3: Critical temperatures of some materials [14]

The field windings contain polesets fabricated using double pancake or racetrack coils of superconductor. The rotor support structure provides support for the HTS field coils. Depending on the rotor topology, the support structure could be made of magnetic material such as iron (for magnetic core rotor) or nonmagnetic material with good heat conduction property, such as aluminum (for aircore rotor). The torque tube acts as connecting support between the part of the rotor at cryogenic temperature and the room temperature shaft end. It also helps to minimize the amount of heat that enters the cryogenic area (thermal isolation). The polesets and support structure are enclosed in a vacuum-sealed cryostat to thermally isolate the HTS coil from surroundings which is at room temperature. The electromagnetic shield located at the outside surface of the cryostat protects the field winding from the magnetic fields produced by the stator winding.

\section{B. Cryogenic cooling system}

The cooling system is considered one of the most important modules in the HTS motor. It is required to cool the HTS winding to the operating temperature determined by the critical temperature of the superconductor. The operating temperature determines the type of coolant to be used.

A brief description of a neon-based cooling system is given as presented in [18]. The cryocooler module is located externally at the non-drive end of the rotor shaft and the refrigerator for condensing the cooling fluid is commercially available Gifford-McMahon (GM) type cryocooler. The cold head is in contact with the condenser of a heat-pipe filled with neon. The heat-pipe reaches into the inner space of the rotor forming an evaporator. Heat is removed from the HTS coils through conduction across a copper heat bus to the evaporator to evaporate the neon. The vapour moves through the same pipe back to the cryocooled condenser and is recondensed. The liquid and gaseous neon coexist in this closed system.

\section{Stator assembly}

The stator assembly houses the armature winding which is usually held at room temperature. The major components of the stator assembly include the following.

- Armature winding

- Winding support

- Machine shield

- Bearing and housing

When superconductors carry ac current there is usually losses (AC losses) [15, 20]. Therefore, armature winding is usually made of copper and the choice of whether to have magnetic teeth or not depends on the type of stator design. For the conventional stator design, the magnetic teeth are retained to guide the flux to the back iron yoke. For the nonconventional stator design, the magnetic teeth are replaced by a nomagnetic support structure. The armature winding in this case is situated in the airgap between the rotor and stator yoke without any magnetic teeth.

\section{HTS Motor DESIGN TOPOLOGIES}

Here we present an overview of some design concepts for the rotor and stator of a superconducting motor. We will also make comparison of these design concepts with conventional machine designs and their suitability for application in Superbus.

\section{A. Rotor design topology}

The rotor design can be differentiated by those with or without magnetic core according to [15, 17, 18, 21, and 22].

\section{Magnetic core rotor design}

The magnetic core rotor design uses the rotor core (usually iron) as part of the magnetic circuit. This design has the advantage that the amount of HTS material used for the field winding is reduced, but suffers from the disadvantage that the magnetic rotor core limits the amount of flux achievable due to saturation of the core. Another advantage of the magnetic core rotor design is that there is a possibility to use the rotor steel of conventional machines. Therefore, this topology is used if the aim is on reducing the amount of required superconductor material (cost saving).

In the magnetic core rotor design there is a choice to either keep the rotor core 'warm' or 'cold'. The warm rotor core design means that the core is kept at ambient temperature. This has the advantage that the so-called 'cold mass' (the amount of rotor material at cryogenic temperature) is minimized. This reduces the cool-down-time or the amount of time required to cool the rotor to its operating temperature. A disadvantage of this design is the need for a rather complex winding support that connects the structures at ambient and cryogenic temperatures. A warm rotor core is suitable for large machines like turbine generators [22].

The cold rotor core design on the other hand means that the core is kept at cryogenic temperature, just like the HTS winding. An obvious advantage is that the winding support is simpler compared with the support for warm rotor core design. 
Since the cold mass of the rotor is now increased, the cooldown-time will be higher than for the warm rotor core design.

\section{Nonmagnetic core rotor design}

The nonmagnetic core rotor or air core rotor design or ironless rotor core does not use the rotor core as part of the magnetic circuit of the machine. The support for the HTS field coils is made from nonmagnetic materials such as alloys of aluminum which has excellent heat conduction property. The major advantage of the air core rotor design is that high flux densities are possible as there is no saturation effect. Therefore the full advantage of HTS technology can be utilized.

The disadvantage is that more HTS material is required which increases the cost. Another disadvantage is that removing the magnetic core introduces complexities and challenges in the design of the supporting structure. Since the rotor has no iron core, the winding support structure must now be designed to transmit all the torque produced by the machine.

\section{B. Stator design topology}

Just like in the rotor design, the stator design can also be differentiated by those with or without magnetic teeth according to $[15,17,18,21$, and 22]. Since superconductors do not have zero losses when they carry ac current (AC losses are present), stator armature windings are usually made of copper. The stator design with magnetic teeth, also called the conventional stator design, retains the magnetic teeth found in stators of conventional machines, to guide the flux to the back iron yoke. However, in the stator design with nonmagnetic teeth, also called the nonconventional stator or air core stator, the magnetic teeth is replaced by a nonmagnetic support structure. The armature winding in this case is situated in the airgap between the rotor and stator yoke without any magnetic teeth.

\section{Stator with magnetic teeth}

This stator design employs the stator design of conventional machines in which stranded copper winding is inserted between the teeth usually made of iron. Just like in conventional machines, the flux density is limited by the saturation of the iron teeth and core loss [16]. This design is used for low flux density machine [15, 17].

The advantage of this design is that it offers the possibility to retrofit existing machines. The use of an existing and well established stator of conventional machines is a good method to easily upgrade such machines to have a more efficient HTS rotor. In some application such as in large power generation, it may be necessary to keep the machine compatible as much as possible with conventional designs.

The disadvantage of this design is that due to saturation, the use of iron teeth limits the flux that can be obtained. A reduction in size of the machine is hardly possible and therefore one major advantage of employing HTS technology (compactness) is already not possible. There is also the presence of harmonics in the magnetic field (slot harmonics) due to the alternating slots and teeth which leads to additional losses. Therefore, this design is used when the aim is on efficiency improvement as in [23, 24].

\section{Stator with nonmagnetic teeth}

In order to fully take advantage offered by the HTS field winding the stator design will have to be different from conventional stator design. The stator design with nonmagnetic teeth, also called the air core stator, is employed to achieve this. In this design, the air core winding is situated in the airgap between the rotor and stator (iron) yoke without any magnetic teeth. The stator slot is composed of nonmagnetic glass fibre reinforced polymer (GFRP) composite having the same permeability with air.

With this design we are also able to achieve compactness in the machine as it is possible to reduce the size of the stator which is not possible using the conventional stator. The omission of magnetic teeth also has other advantages: the air gap flux density is not limited by the saturation of the iron teeth, therefore high flux is achievable; negligible harmonics in the magnetic field is generated due to absence of slots (slot harmonics), therefore there will be very small additional losses; and, noise due to the vibration of teeth is eliminated.

However, this design has the disadvantage that this stator design is completely new and its technology is not proven. Also, since there are no iron teeth, heat removal is more difficult as the presence of iron teeth helps in heat conduction.

\section{LOSS CONSIDERATION}

This section discusses the losses to be expected in the HTS motor in comparison with losses from conventional machines according to $[7,13,15,16,25$ and 26]. The major losses that occur include the following.

- Stator copper losses

- Iron losses

- Friction and windage losses

- Rotor losses (including power for cooling)

The losses in the HTS machine are dominated by stator copper losses. According to $[7,13]$ this accounted for $86 \%$ of the total losses, and about $55 \%$ of the total losses according to [15]. Therefore further improvement in machine efficiency can be achieved by the reduction of losses in the armature winding. A good method of cooling the stator winding will help reduce the copper losses.

The friction and windage losses are reduced to about $30 \%$ of their value in a conventional machine of similar rating [13, 15 and 16] because the HTS machine size and weight are low. With air core stator designs, the iron losses in the HTS machine are about $35 \%$ that of a conventional machine of similar rating and at rated conditions of speed and load according to $[15,16]$. This is possible because less iron mass is used in the air gap winding. The rotor losses including cooling power for the HTS field windings account for about $10 \%$ [7] to $20 \%[15,16]$ of the total losses. As a result of the air gap winding with no iron teeth in the stator core, there is very minimal harmonics in the air gap-field. This means that additional losses are very low. 


\section{HTS MOTOR AND SUPERBUS}

High temperature superconducting motor can be employed for applications where weight and volume reduction is important such as in Superbus. The major driving force for HTS application in Superbus is the possibility to achieve a reduction in weight/size and losses of the motor. In this section we give a summary of the design choices that are attractive for our application. A discussion on the expected reduction in weight, volume and losses is also presented.

Based on the available rotor and stator topologies, the rotor and stator design suitable for Superbus application are identified below.

- The nonmagnetic core rotor design in which support for the HTS field coils is made from nonmagnetic materials such as alloys of aluminum with excellent heat conduction property. This design allows us to achieve high flux densities as there are no saturation effects so that full advantage of HTS technology can be utilized.

- The nonconventional stator design or air core stator in which the iron teeth is removed. Instead the stator slot is composed of nonmagnetic glass fibre reinforced polymer (GFRP) composite having the same permeability as air. This design is suitable because it is possible to achieve compactness through reduction of the size of the stator.

The discussions available in literature suggest a reduction in losses of about $50 \%$. There is a high contribution of copper losses to the total losses that occur in HTS motor accounting for up to $86 \%$ of the total losses in some cases. Therefore, focus in our design is to develop concepts to further cool the stator winding in order to reduce the copper losses.

The achieved efficiency of HTS motor reported in literature is $97 \%$ to $98.7 \%[15,18]$. The HTS motor in [18] has similar power and speed rating $(380 \mathrm{~kW}, 1500 \mathrm{rpm})$ with Superbus motor $(300 \mathrm{~kW}, 1600 \mathrm{rpm})$ : the reported efficiency was $97 \%$. However, this was a prototype machine built by Siemens as a proof of concept of the viability of HTS machines. This HTS motor was not optimized. Therefore, it is safe to assume that an improvement in efficiency can be expected for the Superbus HTS motor. This is especially true if we develop some concepts that will cool the stator winding and reduce the copper losses.

According to [15] a volume reduction of $82 \%$ and weight reduction of $63 \%$ compared to a conventional machine was achieved. While this was a 4 MVA generator whose rating far exceeds that of the Superbus motor, results from [26] suggests a possibility to at least achieve $50 \%$ reduction in weight and volume. This machine also has similar rating with Superbus motor. The maximum allowable weight of Superbus is $10,000 \mathrm{~kg}$. Therefore, a reduction in the weight and size will further reduce the rolling resistance and create room for more components or passengers.

\section{CONCLUSION}

In this paper, we have presented two ways to design the rotor and two ways to design the stator and identified the most suitable design option for application in Superbus. In order to achieve reduction in three parameters (weight, size and losses) which is important to Superbus, the nonmagnetic core rotor and aircore stator design is suitable. It seems possible to achieve $50 \%$ reduction in weight, size and losses for an HTS motor of similar rating with Superbus. The development of concepts for cooling the stator winding will lead to further reduction in losses and therefore improvement in efficiency.

\section{REFERENCES}

[1] K. Yamaguchi, et al, "70 MW class super-conducting generator test", IEEE Trans. Appl. Superconduct., vol. 9. pp. 1209-1212, June 1999.

[2] J.A Fealey, W.D Jones, T.A. Keim and T.E. Laskaris, "Comprehensive test and evaluation of a 20 MVA superconducting generator", IEEE Trans. Power App. Syst., vol. PAS-104, no. 6, pp. 1484-1490, June, 1985.

[3] P.W. Eckels and G. Snitchler, "5MW high temperature superconductor ship propulsion motor design and test results", Naval Engineers Journal, vol. 117, no. 4, pp. 31-36, 2005.

[4] S.S. Kalsi, et al, "Development status of rotating machines employing superconducting field windings", Proceedings of the IEEE, vol. 92, no. 10, pp. 1688-1704, October 2004.

[5] S. S. Kalsi, N. Henderson and J. Voccio, "Superconductor motors for high speed ship propulsion", American Superconductor Corporation, Westborough, MA. Available at:

http://www.amsc.com/products/motorsgenerators/documents/HTSMotors forHighSpeedShipsASNE.pdf.

[6] J. K. Hulm, E. F. McCann, C. J. Mole, and J. H. Parker, Jr., "Development of a 5 MVA superconducting generator-general aspects, "IEEE Power Engineering Winter Meeting, New York, paper no. C73259-9, January 1973.

[7] B. Gamble, S. Kalsi, G. Snitcheler, D. Madura and R. Howard, "The Status of HTS Motors", Presented at the IEEE PES Meeting, Chicago, Illinois, July 2002, IEEE CD ISBN 0-7803-7518-1.

[8] C. Flick, W.R. McCown and J.H. Parker Jr., "General design aspects of a 300MVA superconducting generator for utility application", IEEE Trans. Magn., vol. MAG-17, no. 1, pp. 873-879, Jan. 1981.

[9] T.A. Keim, T.E. Laskaris, J.A. Fealey and P.A. Rios, "Design and manufacture of a 20 MVA superconducting generator", IEEE Trans. Power Appa. \& Syst., vol. PAS-104, no. 6, pp.1474-1483, June 1985.

[10 J.A. Melkert, "Superbus: using aerospace technology to make high speed public transport more sustainable", European Transport Conference, Leeuwenhorst Conference Centre, The Netherlands, October, 2007.

[11] A. Terzi, and W.J. Ockels, "Superbus concept relies on lightweight composite construction", Reinforced Plastics, Elsevier Ltd, vol. 52, Issue 2, February 2008, pp. 28-29, 31-33, 35.

[12] J. Parker, R. Blaugher, A. Patterson, P. Vecchio, and J. McCabria, "A high speed superconducting rotor", IEEE Trans. Magn., vol. MAG-13, no. 1, pp. 755-758, January 1977.

[13] D. Lambrecht, "Status of development of superconducting AC generators", IEEE Transactions on Magnetics, vol. 17, no. 5, pp. 15511669, September 1981.

[14] R. Schiferl "Rockwell Automation Superconducting Motor Technology", Rockwell Automation, Richmond Heights, Ohio, available at www.energetics.com/meetings/ohiosupercon/pdfs/e_super_motors.pdf

[15] G. Kluas, M. Wilke, J. Frauenhofer, W. Nick, H. Nuemuller, "Design Challenges and Benefits of HTS Synchronous Machines", IEEE Power Engineering Society General Meeting, June 2007, Digital object identifier 10.1109/PES.2007.385756.

[16] J.D. Edick, R.F. Schiferl, and H.E. Jordan, "High Temperature Superconductivity Applied to Electric Motors" IEEE Transactions on Applied Superconductivity", vol. 2, No. 4, pp. 189-194, December 1992.

[17] J. Frauenhofer, J. Grundmann, G. Klaus and W. Nick, "Basic Concepts, Status, Opportunities, and Challenges of Electrical Machines utilizing High-Temperature Superconducting (HTS) Windings", Proceedings of $8^{\text {th }}$ European Conference on Applied Superconductivity (EUCAS 2007), Journal of Physics: Conference Series 97 (2008).

[18] W. Nick, et al, " $380 \mathrm{~kW}$ Synchronous machine with HTS rotor windings - development at Siemens and first test results", Elsevier Science, Physica C 372-376, pp. 1506-1512, 2002. 
[19] M.H. Sohn, "Performance of High Temperature Superconducting Field Coils for a 100 HP Motor", IEEE Trans. Appl. Supercond., vol. 14, no. 2, pp. 912-915, June, 2004.

[20] P.K. Ghoshal, et al, "Experimental set up to measure AC losses of HTS in rotating magnetic field", IEEE Trans. Appl. Supercond., vol. 17, no. 2, pp. 3199-3202, June 2007.

[21] Y.K Kwon, et al, "Development of a $100 \mathrm{hp} \mathrm{synchronous} \mathrm{motor} \mathrm{with}$ HTS field coils", IEEE Trans. Appl. Supercond., vol. 15, no. 2, pp. 21942197, June 2005.

[22] B. Gamble, G. Snitchler, and S.S. Kalsi, "HTS Generator Topologies", IEEE Xplore, available at

http://ieeexplore.ieee.org/stamp/stamp.jsp?arnumber=01709646
[23] L. Salasoo, K.G Herd, E.T. Laskaris, and M.V.K. Chari, "Design and analysis of a novel superconducting generator", IEEE Int. Electric Machines and Drives Conf., (IEMDC), Milwaukee, WI, USA, pp. MA2/2.1-MA2/2.3, May 1997.

[24] K.K. Weeber, et al, "High temperature superconducting generators", IEEE 2003 Power Engineering Soc. Annual Meeting, Emerging Technologies Panel Session, Toronto, ON, Canada.

[25] G. Nerowski, J. Frauenhofer, G. Ries, W. Nick, and H.-W. Neumiiller, "Advances and prospects of HTS rotating machine development at Siemens", IEEE Power Engineering Society General Meeting, vol. 2, pp. 2052-2055, June, 2004.

[26] M. Frank, et al, "Long-Term Operational Experience With First Siemens $400 \mathrm{~kW}$ HTS Machine in Diverse Configurations", IEEE Trans. Appl. Supercond., vol. 13, no. 2, pp. 2120-2123, June 2003. 